\title{
Performance Study of a Floricultural Greenhouse Surrounded by Shallow Water Ponds
}

\author{
Debajit Misra* and Sudip Ghosh
}

\section{Department of Mechanical Engineering, Indian Institute of Engineering Science and Technology, Shibpur, Howrah, India, 711103}

\begin{abstract}
In the present paper, an innovative low energy-intensive evaporative cooling system has been proposed for greenhouse application in near-tropical regions dominated by hot climate. The system can operate under dual- ventilation mode to maintain a favourable microclimate inside the greenhouse. A single ridge type un-even span greenhouse has been considered, targeting a few species of Indian tropical flowers. The greenhouse has a continuous roof vent as well as adjustable side vents and is equipped with exhaust fans on top and roll-up curtains on the sides. The greenhouse is surrounded by shallow water ponds outside its longitudinal walls and evaporative surfaces partially cover the free water surface. Inside the pond, low cost evaporative surfaces are so placed that they form air channels. Thus, outside air flows through the channels formed by the wetted surfaces over the water surface and undergoes evaporative cooling before entering the greenhouse. A simplified theoretical model has been presented in this paper to predict the inside greenhouse air temperature while ambient weather data are used as model inputs. The study reveals that during average radiation periods, the greenhouse can depends solely on natural ventilation and during peak radiation hours fan-induced ventilation is needed to maintain the required level of temperature. It is seen that under dual-ventilation mode greenhouse, temperature can be kept $3-6{ }^{\circ} \mathrm{C}$ lower than ambient temperature when saturation effectiveness is 0.7 and with $75 \%$ shading.
\end{abstract}

Keywords: Greenhouse, Evaporative Cooling, Ventilation, Saturation Effectiveness, Wetted Surface

Article History: Received February 25th 2017; Received in revised form April 14th 2017; Accepted May 4th 2017; Available online How to Cite This Article: Misra, D. and Ghosh, S., (2017) Performance Study of a Floricultural Greenhouse Surrounded by Shallow Water Ponds. International Journal of Renewable Energy Development, 6(2), 137-144.

https://doi.org/10.14710/ijred.6.2.137-144

\section{Introduction}

Greenhouse technology has been evolved to create a controlled environment, which favours the plant production all through the year or part o the year as per plant requirement. The natural environment in a greenhouse is modified by a suitable technique to achieve the optimum plant growth and yields. The primary environmental parameter traditionally controlled is temperature. Greenhouses for cold countries provide with heating systems to overcome the extreme cold. However, greenhouses in tropical and sub tropical countries need cooling to mitigate temperature. Nowadays various cooling techniques are being incorporated for greenhouses to control temperature. Evaporative cooling technique is one of the viable options by which greenhouse temperature can be kept lower during hot periods. In many cases, evaporative cooling is done with the help of fan pad ventilation system. Though natural ventilation with evaporative cooling is a low energy consuming method, it cannot be suitable for high solar radiation periods. Thus, both natural as well as fan-induced ventilation with evaporative cooling offer better flexibility and reduced energy cost. The present paper is intended to develop such a greenhouse model, which can be operable under dual- ventilation mode by consuming low energy.

Many research works have been carried out on greenhouse cooling techniques and notable works are mentioned here. Papadakis et al. (1996) carried out their observation on natural ventilated plastic greenhouse equipped with continuous roof and side openings. They have used tracer gas technique for measuring ventilation and leakage rate. Kittas et al. (1997) presented a model to find the air exchange rate a Mediterranean greenhouse with ridge and side openings and validated with experimental data. Teitel and Tanny (1999) developed a theoretical model for naturally ventilated greenhouse in a four-span

\footnotetext{
*Corresponding author:dmbesu@gmail.com
} 
Citation: Misra, D. and Ghosh, S., (2017) Performance Study of a Floricultural Greenhouse Surrounded by Shallow Water Ponds. Int. Journal of Renewable Energy Development, 6(2),137-144, https://doi.org/10.14710/ijred.6.2.137-144

P a g e | 138

greenhouse. The theoretical model was calibrated against experimental results. The greenhouse has continuous vertical roof windows to control the temperature and humidity. Arbel et al. (1999) developed a thermal model of a greenhouse system fitted with fogging system. They made a comparative performance study of a greenhouse equipped with fog system as well as with fan-pad system. It was reported that fog cooling system performed better than the fanpad evaporative cooling system. Roy et al. (2002) have presented a study on convection and ventilation processes for the greenhouse microclimate. Semiempirical models were used in the studies and ventilation processes associated with Bernoulli equation. Jain and Tiwari (2002) have developed a theoretical model for greenhouse system. They have conducted an experiment on fan-pad evaporative cooling system in a $24 \mathrm{~m}^{2}$ greenhouse and examined that the greenhouse air temperature was reduced 4-5 ${ }^{0} \mathrm{C}$ lower than the ambient by using fan and pad system. They have observed that optimum greenhouse cooling depend on length of greenhouse and height of the cooling pad. Shu-zhen et al. (2005) presented a thermal model for a naturally ventilated greenhouse to predict greenhouse microclimate. The model was experimentally validated against a $504 \mathrm{~m}^{2}$ polyethylene three-span greenhouse equipped with insect proof screen. The model was based on Roof ventilation and combined roof and sidewall ventilation. They also carried out a performance study on wind speed and window opening height on the air temperature variation. Fuchs et al. (2006) developed a procedure to evaluate the latent heat cooling by means of crop transpiration and free water evaporation from wet fan and pad system. Ganguly and Ghosh (2007) have carried out a theoretical model of a fan-pad ventilated floriculture greenhouse to find the greenhouse average temperature. The model performance study was based on climatic data used for Kolkata. They have also presented a parametric study by varying greenhouse shading and ventilation rate. Again, Ganguly and Ghosh (2009) developed a greenhouse thermal model to show the equilibrium greenhouse temperature considering naturally ventilated greenhouse. Both side and roof vents was taken under consideration in their model. The model has been validated with an experimental greenhouse. Longitudinal distributed cooling pads for greenhouse system were proposed and studied by Misra and Ghosh (2013). In their greenhouse system the induced draught fans were fitted at the top of the roof. They developed a thermal model to predict the inner temperatures. The model results had been validated with a model present in literature. It was observed that inner temperature decreased by $5-7{ }^{\circ} \mathrm{C}$ below the ambient temperature providing 1.2 ACM ventilation rate and 50\% canopy shading during summer in Kolkata. White (2015) presented a cooling system comprised of vent, fan and fog (VFF) for a large Velno greenhouse in hot and dry seasons. The greenhouse was shaded by $61 \%$ shading screen and fitted with high pressure fog nozzles. There were eighteen exhaust fans, nine in each of the north and south gable ends walls while others were placed on the concrete nib walls, close to ground level. The fans provided a nominal air flow of $0.0188 \mathrm{~m}^{3} \mathrm{~s}^{-1} \mathrm{~m}^{-2}$. It was reported such kind of cooling arrangements inside temperature of the greenhouse could be lowered in the range of 5.8 to $10.8^{\circ} \mathrm{C}$ than the ambient temperature. Again, Misra and Ghosh (2017) developed a thermal model for a fog-cooled greenhouse under natural ventilation and validated the model with an experimental arched shape plastic greenhouse situated in Indian climatic condition. They reported that with low pressure fogging system with suitable ventilation greenhouse inside temperature could be maintained 2 $5{ }^{\circ} \mathrm{C}$ lower than ambient temperature. Thipe et al. (2017) reviewed the effect of naturally ventilated system and fan-pad system for the greenhouse application in arid climatic regions.

The survey of contemporary literatures show that the existing greenhouse works are based either on natural ventilation with or without fogging or on fan pad evaporative cooling to maintain desired microclimate. However, none of the above-mentioned work is focused on dual ventilation with external evaporative cooling. Therefore, an initiative has been undertaken to develop the present work.

In conventional naturally ventilated greenhouses, the appropriate microclimate during the whole season cannot be maintained, as this type of ventilation is not enough to reduce high inside temperature. The proposed greenhouse can overcome such limitations as it operates under dual-ventilation mode with evaporative cooling of air. For average radiation hours, natural ventilation with evaporative cooling is sufficient to cool greenhouse temperature. During the peak radiation hours, fans (placed above gutter) assist to ventilate air through the greenhouse. Two covered ponds are located outside along the side walls (longitudinal walls of the greenhouse) to cool the air and each of the sidewalls has continuous opening (side vent) for the passage of conditioned air. Thus, the construction expenses of the proposed system remain low and save higher energy requirement compared to the conventional fan-pad greenhouse. In this work, we present a thermal model for the cooling and ventilation system and also show the predicted performance of such system under varying climatic condition on representative days.

\section{Materials and Methods}

In the present case, a greenhouse has been considered with of $6 \mathrm{~m}$ width and $30 \mathrm{~m}$ length made which is covered with Fiber Reinforced Plastic (FRP). The greenhouse is east west oriented and considering continuous side and ridge opening. 


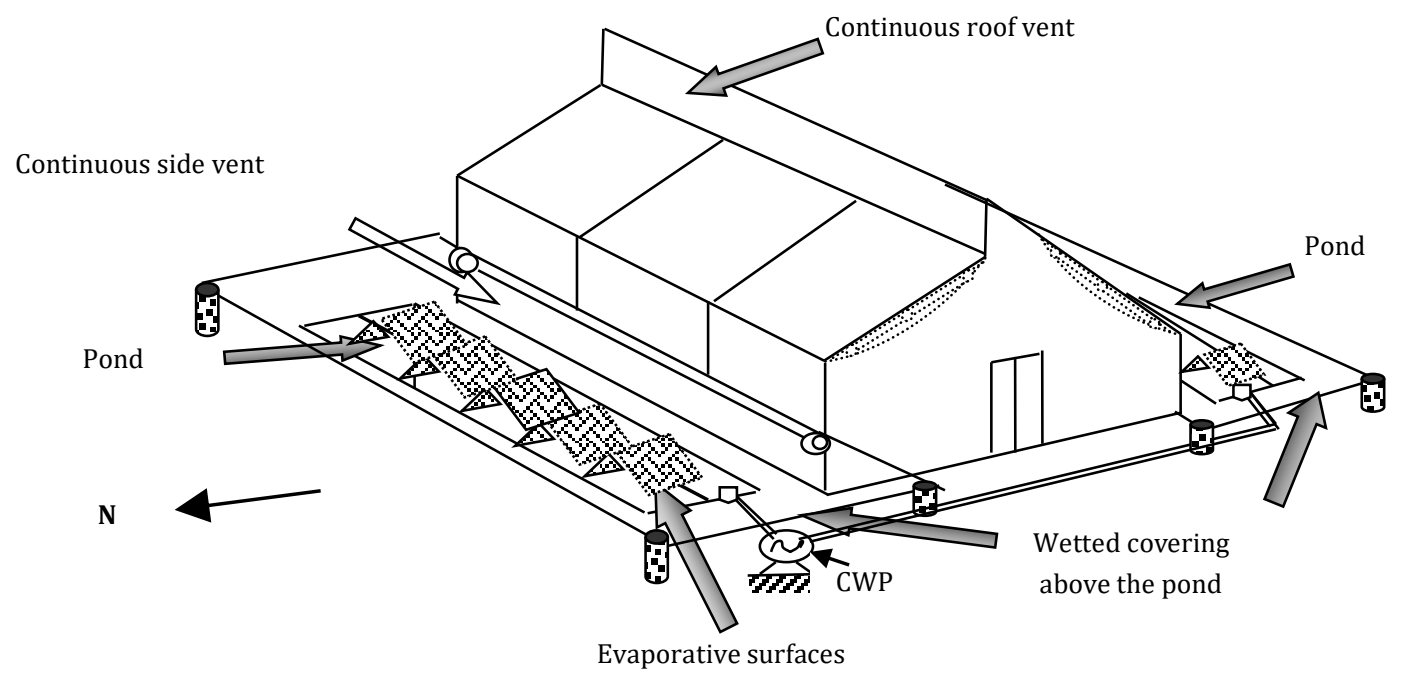

Figure 1(a) General arrangement of the greenhouse system

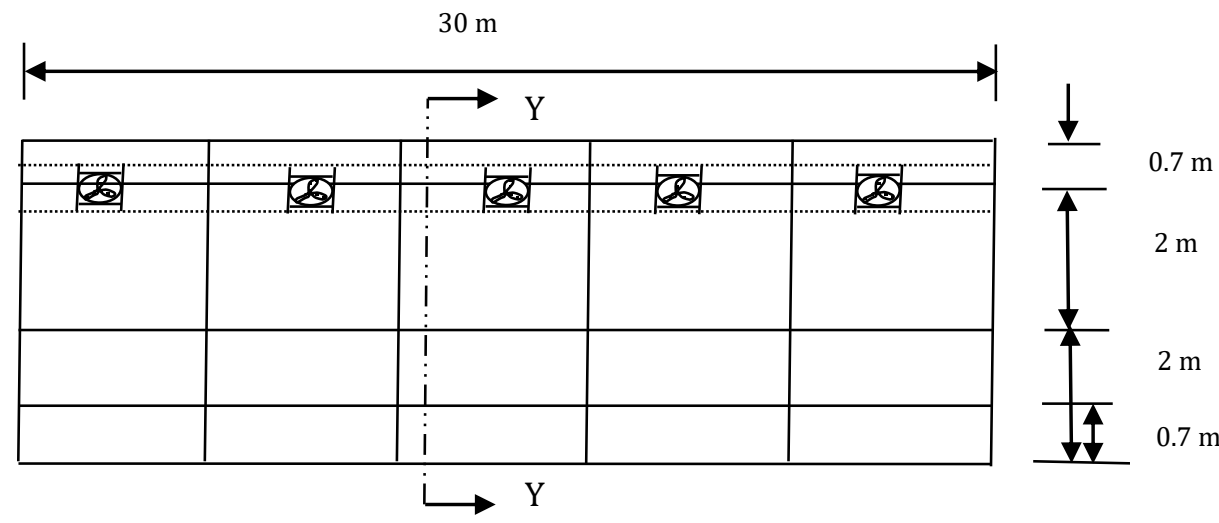

Figure 1(b). Side elevation (North) of the greenhouse

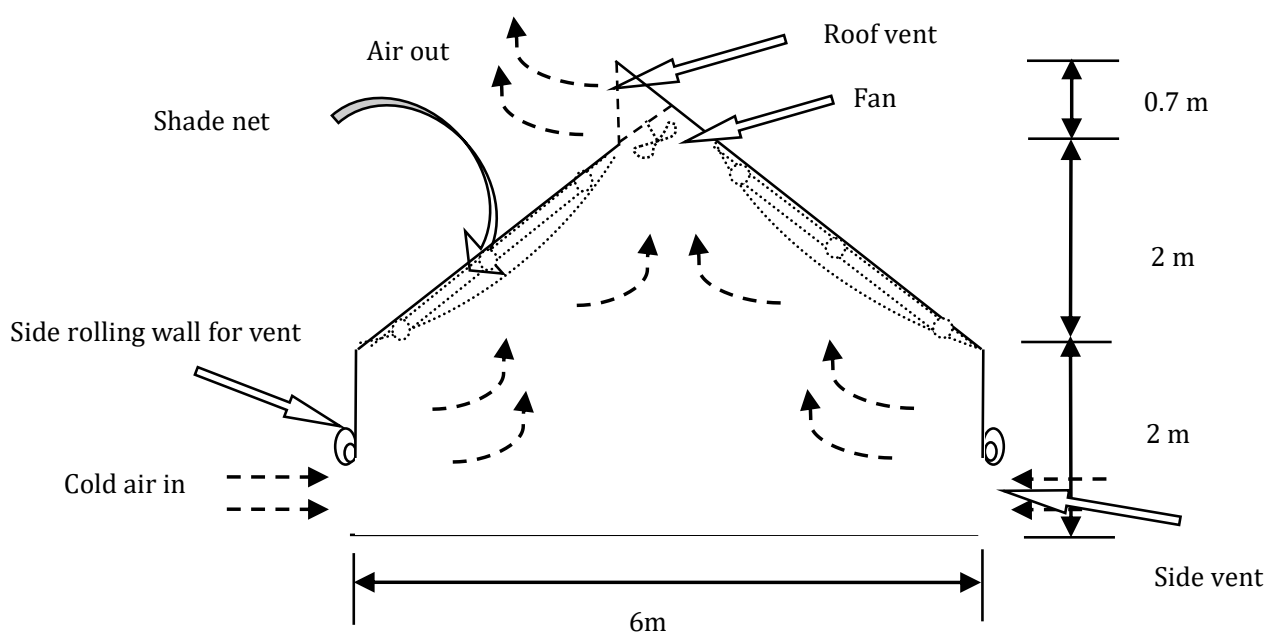

Figure 1(c). Sectional elevation of Y-Y 
Citation: Misra, D. and Ghosh, S., (2017) Performance Study of a Floricultural Greenhouse Surrounded by Shallow Water Ponds. Int. Journal of Renewable Energy Development, 6(2),137-144, https://doi.org/10.14710/ijred.6.2.137-144

P a g e | 140

Figure 1 represents the general arrangement of the proposed greenhouse system. The ridge height of the greenhouse is $4.7 \mathrm{~m}$ and gutter height is $2 \mathrm{~m}$. The sidewalls are fitted with roll up curtain to close and open the side vents as per requirement. In general, the side vents (on the north and south walls) maintain 0.7 $\mathrm{m}$ from the floor. The greenhouse has been provided a continuous roof vent of $30 \mathrm{~m}$ long and $21 \mathrm{~m}^{2}$ area. The shade nets are incorporated beneath of the both canopies in inclined manner. The fans are mounted on the roof and just above the shade nets of the greenhouse as shown in Fig.1. On the outside of the greenhouse, two shallow covered ponds are situated. A covering is housed at a certain height to protect the water from getting warm in the sun. On the pond surface along the north and south walls, some low-cost evaporative surfaces are placed in such a manner that they make numerous channels as shown in figure1. Thus, due to wind effect and buoyant effect, outside air flows through the wetted channels into the greenhouse and reduces the air temperature. The greenhouse is also equipped with fans, which are placed at top to increase ventilation rate as per the requirement. When the greenhouse is operating under natural or fanassisted system, the roof vents is fully opened. The evaporative surfaces located on pond are wetted with water. A circulating water pump is installed outside the greenhouse to transport a constant supply of water to the evaporative surfaces, provide the required water for plants, to maintain desired water level of the ponds and to wet the cover.

\section{Model Description}

The basic energy balance equation is based on the following assumptions.

i. Heat flow is considered as one-dimensional.

ii. Negligible amount of heat absorbed by structural members.

iii. There is no radiative heat exchange from greenhouse walls and canopy as temperature difference is low.

Total amount of heat into the greenhouse due to solar radiation is given by

$$
Q=\sum(1-S F) A_{i} I_{t i}
$$

Where $A_{i}$ is the area of the surface ' $\mathrm{i}$ ' and $\mathrm{I}_{\mathrm{ti}}$ is the intensity of transmitted solar radiation into the greenhouse through that surface. SF is the shading factor for greenhouse roof and walls.

The transmitted solar radiation $\left(\mathrm{I}_{\mathrm{t}}\right)$ into the reenhouse through a surface area is given as

$$
I_{t}=\sum I_{b} R_{b} \tau_{b}+I_{d} R_{d} \tau_{d}+\left(I_{b}+I_{d}\right) R_{r} \tau_{r}
$$

Where $I_{b}$ and $I_{d}$ are intensity of beam and diffuse radiation respectively. $R_{b}, R_{d}$, and $R_{r}$ are tilt factors for beam, diffuse and reflected radiation respectively. $\tau_{b}$ is the transmissivity of the beam radiation is taken a value of 0.8 for the cover material (FRP). $\tau_{r}$ and $\tau_{d}$ are the transmissivity of the reflected and diffuse radiation which are assumed to be constant having the value of 0.76 (Misra and Ghosh, 2013).

A part of incoming solar radiation, after transmitting through the greenhouse cover is absorbed by the floor and vegetation. Thus, Sensible heat gain of greenhouse air can be written as

$$
Q_{s}=\left\lfloor C\left(1-\alpha_{p}\right)-\left(1-\alpha_{f}\right)(1-C)\right\rfloor Q
$$

Where $\mathrm{C}$ is fraction of greenhouse floor covered with plantation; $\alpha_{p}$, and $\alpha_{f}$, are heat absorptivity values for and floor respectively.

\subsection{Natural Ventilation Model}

In an earlier paper, Ganguly \& Ghosh [2009] have discussed how the model for natural ventilation could be evolved by first considering a closed-vents condition for the greenhouse followed by an open-vents condition. A similar approach is taken in the present case with the exception that in the present case inlet air is conditioned after flowing over the water pond.

The energy balance equation for a closed and properly sealed greenhouse (when both roof and side vents are closed), under no ventilation condition is given by

$$
m_{g} C_{p} \frac{d T_{g}}{d t}=Q_{s}-h A_{c}\left(T_{g}-T_{a}\right)
$$

Where $m_{\mathrm{g}}$ is the mass of the greenhouse air in $\mathrm{kg} ; c_{\mathrm{p}}$ is the specific heat of air in $\mathrm{J} /(\mathrm{kgK}) ; T_{g}$ is greenhouse air temperature in $\mathrm{K} ; T_{a}$ is the temperature of ambient air in $\mathrm{K} ; Q_{s}$ is the heat gain by the air in $\mathrm{W} ; t$ is the time in $\mathrm{s} ; \mathrm{h}$ is heat transfer coefficient in $\mathrm{W} / \mathrm{m}^{2} \mathrm{~K} ; A_{c}$ is the greenhouse covering area in $\mathrm{m}^{2}$.

The greenhouse temperature goes to the maximum when all vents are closed and there will no further rise in temperature with time, since at this point the net sensible heat gain maintains equilibrium with the heat loss to the environment through the coverings (Shu-zen et al., 2005).

After maximum temperature gain, when all vents are opened, greenhouse temperature gradually decreases until it reaches to the equilibrium condition. Thus, energy equation can be given as

$m_{g} C_{p} \frac{d T_{g}}{d t}=Q_{s}-h A_{c}\left(T_{g}-T_{a}\right)-m_{v a} C_{p}\left(T_{g}-T_{w e t}\right)$

Where $\mathrm{m}_{\mathrm{va}}$ is the mass flow rate of air in $\mathrm{kg} / \mathrm{s}$ and $T_{\text {wet }}$ is the temperature of conditioned air in $\mathrm{K}$.

The temperature of conditioned air $\left(\mathrm{T}_{\mathrm{wet}}\right)$ depends on wet-bulb temperature $\left(\mathrm{T}_{\mathrm{wb}}\right)$ of air 
$T_{w e t}=\left[T_{a}-\varepsilon\left(T_{a}-T_{w b}\right)\right]$

Where, $\varepsilon$ is saturation effectiveness of wetted surfaces. When the greenhouse is operated without evaporative cooling arrangement, $\mathrm{T}_{\text {wet }}$ would be replaced by $\mathrm{T}_{\mathrm{a}}$.

In natural ventilation mode, two main driving forces are predominant, one is wind effect, which happens due to pressure difference around the vents, and other is buoyant effect (stack effect), which occurs due to the air density variation between inside and outside. In the present model, both the stack effect and wind effect are considered. The mass flow rate by the natural ventilation mode (considering wind effect and stack effect) was expressed by Kittas et al. (1997).

$$
m_{v a}=\rho C_{d}\left[\begin{array}{l}
\left(\frac{\left(A_{r} A_{s}\right)^{2}}{A_{r}^{2}+A_{s}^{2}}\right)\left(2 g \frac{T_{g}-T_{w e t}}{T_{\text {wet }}} H_{r s}\right) \\
+\left(\frac{A_{r}+A_{s}}{2}\right)^{2}\left(C_{r s} v\right)^{2}
\end{array}\right]^{0.5}
$$

Where $\mathrm{A}_{\mathrm{r}}$ and $A_{\mathrm{s}}$ are the respective roof and side ventilation areas in $\mathrm{m}^{2} ; H_{\mathrm{rs}}$ is the vertical distance between the midpoints of the side and roof openings in metre $(\mathrm{m}) ; \mathrm{C}_{\mathrm{d}}$ and $C_{\mathrm{rs}}$ are the discharge coefficient and wind effect coefficient respectively; $\rho$ density of air $\left(\mathrm{Kg} / \mathrm{m}^{3}\right) ; \mathrm{v}$ is the greenhouse outside wind velocity.

Eqn. 5 has been solved simultaneously in every increment of time interval using equation 7 to find out greenhouse equilibrium temperature $\left(\mathrm{T}_{\mathrm{g}}\right)$. The value of $C_{\mathrm{d}}$ for vertical rectangular vent has been considered 0.65 and the value of $C_{\mathrm{rs}}$ has been taken 0.14 (Roy et al., 2002).

\subsection{Fan-induced Ventilation Model}

In fan-induced ventilation average greenhouse air temperature can be found by following energy balance equation

$$
Q_{s}=h A_{c}\left(T_{g}-T_{a}\right)-\rho V C_{p}\left(T_{f a n}-T_{w e t}\right)
$$

Where, right part of the equation indicates energy convection in-between the greenhouse covering to ambient and energy ventilation by the ID fans.

Where, $\mathrm{V}$ is the volume flow rate of the ID fan, which can be expressed as

$$
V=(A C M \times L \times B \times H) / 60
$$

Where, $\mathrm{H}$ is the effective height of the greenhouse when hypothetical shape of the greenhouse is considered as a parallelepiped.

The average greenhouse temperature $\left(\mathrm{T}_{\mathrm{g}}\right)$ can be considered as arithmetic mean of the conditioned air temperature and the maximum greenhouse air temperature at fan end $\left(\mathrm{T}_{\mathrm{fan}}\right)$ and expressed as

$$
T_{g}=\frac{T_{f a n}+T_{w e t}}{2}
$$

Table 1

Parameter value used

\begin{tabular}{clc}
\hline Parameters & Dimensions & Value \\
\hline $\mathrm{A}_{\mathrm{c}}$ & $\mathrm{m}^{2}$ & 345 \\
$\mathrm{C}_{\mathrm{p}}$ & $\mathrm{J} / \mathrm{mK}$ & 1005 \\
$\rho$ & $\mathrm{Kgm}^{-3}$ & 1.2 \\
$\varepsilon$ & dimensionless & 0.7 \\
$\mathrm{~h}$ & $\mathrm{~W} / \mathrm{m}^{2} \mathrm{~K}$ & 4.5 \\
$\mathrm{a}_{\mathrm{p}}$ & dimensionless & 0.45 \\
$\mathrm{a}_{\mathrm{f}}$ & dimensionless & 0.3 \\
$\mathrm{C}$ & dimensionless & 0.9 \\
$\mathrm{v}$ & $\mathrm{m} / \mathrm{s}$ & 1.2
\end{tabular}

\section{Results and Discussion}

The computer codes on $\mathrm{C}$ have been developed to predict the greenhouse air temperature. In case of natural ventilation, the program is used to simulate two distinct considerations: first to predict maximum temperature when all vents (roof and side vents) of the greenhouse are considered as closed and second to predict the final equilibrium temperature when all vents are fully opened. The code had been developed and experimentally validated in the earlier paper. In the present paper, similar code has been taken by considering evaporative cooling of air to predict the greenhouse equilibrium temperature.

The performance study of the greenhouse model has been executed by available solar radiation and temperature data published for Kolkata (Tiwari, 2002) considering a suitable relative humidity. The output of the present natural ventilation model is also compared with the earlier Ganguly \& Ghosh model (2009) that considered no surrounding water body. The saturation effectiveness of evaporative surfaces depends on the material and surrounding conditions. Here, 70\% saturation effectiveness is considered as a base case and effect of its variation has been studied.

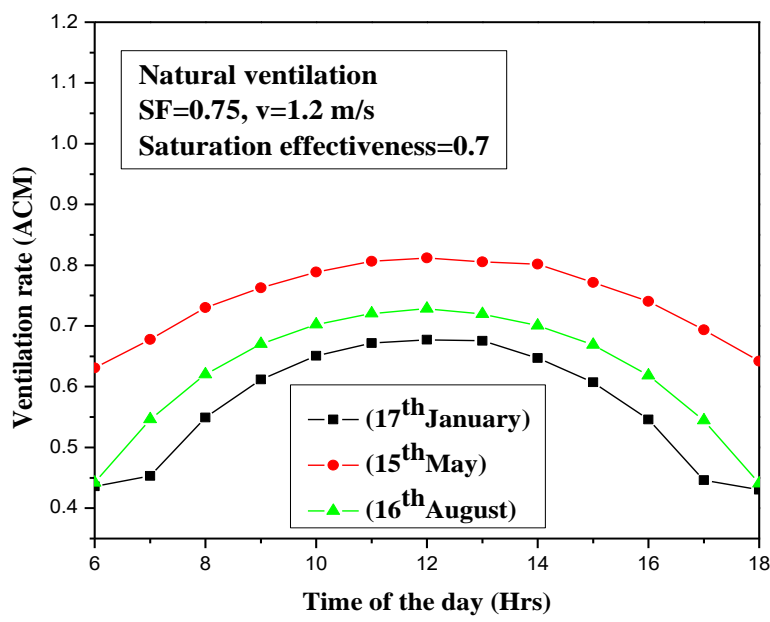

Fig. 2 Hourly variation of mass flow rate under natura ventilation for the representative days of the months 
Citation: Misra, D. and Ghosh, S., (2017) Performance Study of a Floricultural Greenhouse Surrounded by Shallow Water Ponds. Int. Journal of Renewable Energy Development, 6(2),137-144, https://doi.org/10.14710/ijred.6.2.137-144

$\mathrm{P}$ a g e | 142

Figure 2 shows the variation of air change rate under natural ventilation mode for different representative days on January, May and August. It is seen that air change rate is more in the month of May as solar radiation intensity is high, moderate for the month of August and minimum for the month of January. The results are obtained considering free air velocity of $1.2 \mathrm{~m} / \mathrm{s}, 75 \%$ shading and a saturation effectiveness of 0.7 . It is seen that air change rate is increasing with hours of the day, as solar radiation increases. Air change rate is more than 0.6 ACM. However, during the mid-day or peak radiation hours, air change rate through the greenhouse does not exceed 0.81ACM. Thus, in order to increase flow rate, fan assisted ventilation may be incorporated to reduce high heat load.

Figure 3 shows the hourly variation of greenhouse air temperature with that of ambient temperature under natural as well as fan-assisted ventilation mode for a given value of shading (75\%) on a representative hot day of May. The free wind velocity is considered as $1.2 \mathrm{~m} / \mathrm{s}$. It is clearly visible that greenhouse temperature is very much high when evaporative cooling is not in use. It is seen that evaporative cooling effectively moderates greenhouse temperature during most of the hours of the day by natural or under fanassisted ventilation. Utilizing natural ventilation, during peak radiation hours (12 to $15 \mathrm{~h}$ ), greenhouse temperature can be kept around $32^{\circ} \mathrm{C}$ when the ambient temperature varies between $33.7-35.8^{\circ} \mathrm{C}$ and incorporating fan-assisted ventilation the maximum greenhouse temperature can be kept below $30^{\circ} \mathrm{C}$ most of the time. From the figure, it is seen that under fanassisted ventilation greenhouse temperature drops by about 4-6 ${ }^{\circ} \mathrm{C}$ below the ambient even during peak radiation hours. The fans are considered as 1.2 ACM ventilation rate. Thus, for high radiation periods, instead of natural ventilation fan assisted ventilation is very much useful.

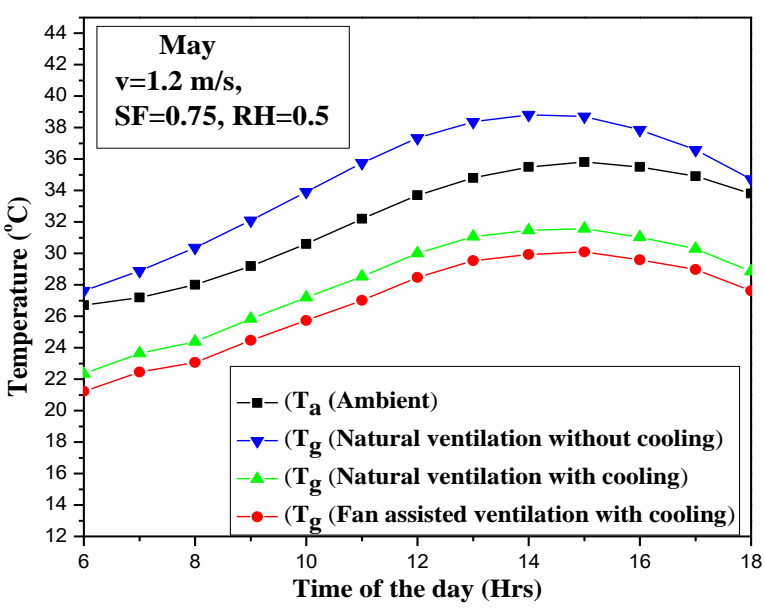

Fig. 3 Hourly variation of greenhouse temperature for a representative day of May under natural as well as fanassisted ventilation
Figure 4 shows the variation of greenhouse air temperature against ambient temperature under natural as well as fan-assisted ventilation on a representative day of August. In India, August is a hot and humid month of the monsoon. The relative humidity is considered to be $75 \%$ and free wind velocity is considered $1.2 \mathrm{~m} / \mathrm{s}$ for every hour of the day. It is seen that due to the low value of wet bulb temperature of the air, inside temperature can be kept acceptable level though the humid condition is not favourable for evaporative cooling. It is seen that evaporative cooling reduces greenhouse temperature around $3-4{ }^{\circ} \mathrm{C}$ below the ambient air under natural ventilation and around $4-5{ }^{\circ} \mathrm{C}$ below the ambient under fan-assisted ventilation. It is observed that with fan-assisted ventilation of 1.2 ACM air change, greenhouse air temperature can be maintained below $27{ }^{\circ} \mathrm{C}$ during the high radiation hours (12-15h).

Figure 5 shows the hourly variation of greenhouse air temperature with that of ambient temperature on January, a representative day in winter under natural ventilation mode. The incident solar radiation in this month is low and for that, shading is taken $50 \%$. The greenhouse temperature is significantly lower than that of natural ventilation without evaporative cooling. Relative humidity is considered to be $50 \%$. It is seen that employing evaporative cooling, the maximum greenhouse temperature during the day is below $23^{\circ} \mathrm{C}$ under natural ventilation. Thus, the greenhouse has not needed fan ventilation in this month.

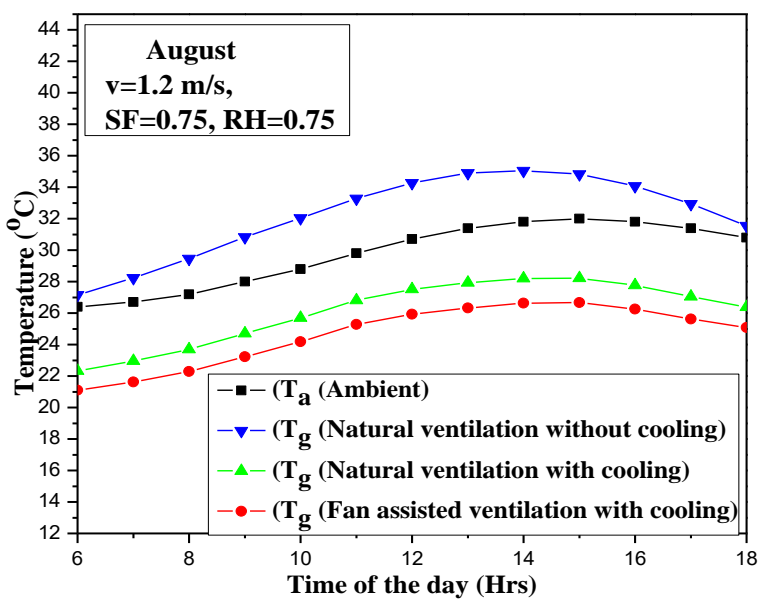

Fig. 4 Hourly variation of greenhouse temperature for a representative day of August under natural as well as fan-assisted ventilation

All of the above cases, it is observed that the results predicted by the model are lower than the results obtained using the Ganguly \& Ghosh model (2009) for natural ventilation without cooling of air. There is a remarkable difference between the outputs of the two as model facilitates evaporative cooling of air.

Following section, sensitivity analysis has been presented in order to study the effect of changing vent opening height, saturation effectiveness and wind velocity on the greenhouse microclimate. The analysis 
was done by the prevailing ambient data taken from Ganguly \& Ghosh model (2009) as input parameters.

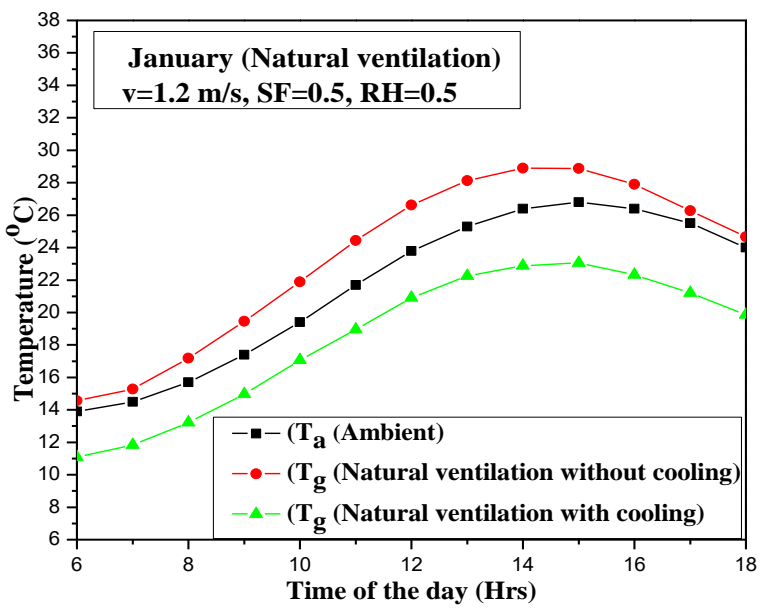

Fig. 5 Hourly variation of greenhouse temperature for a representative day of January under natural ventilation

Figure 6 shows the effect of side vent opening on greenhouse temperature and ventilation rate under natural ventilation with evaporative cooling. It is seen from the figure that as the height of side vent opening increases, ventilation rate increases consequently greenhouse temperature decreases. It is observed that after the certain height of the ventilator, further increase in ventilation height, the temperature is not decreasing sharply due to an almost constant rate of air exchange. It can be seen that for ventilation height in between 1.4-2 $\mathrm{m}$ ventilation rate near about steady.

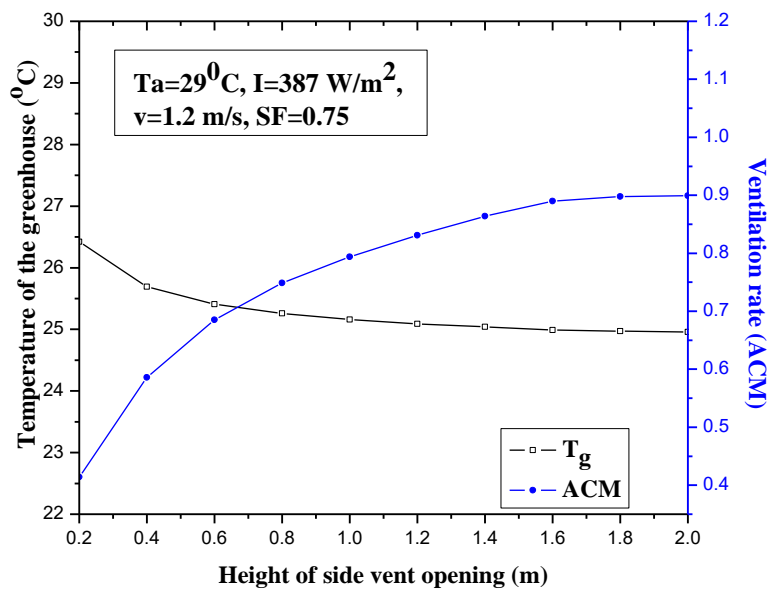

Fig. 6 Effect of height of side vent opening on greenhouse temperature and ventilation rate

Figure 7 shows the effect of saturation effectiveness on greenhouse temperature and ventilation rate under natural ventilation keeping ambient conditions unchanged. It is seen that increase in saturation effectiveness greenhouse temperature considerably decreases. It is seen that increase in saturation effectiveness, greenhouse temperature considerably decreases. The variations of curves are linear.
However, a little effect occurs on ventilation rate though saturation effectiveness constantly increasing. It is observed that greenhouse temperature can be maintained sufficiently lower than ambient by good quality evaporative surfaces, which have high saturation effectiveness.

Figure 8 shows the effect of free wind velocity on greenhouse temperature and ventilation rate under natural ventilation keeping ambient conditions unchanged. From the figure, it is observed that increase in free wind velocity increases air exchange rate and decreases the greenhouse temperature. It is seen that with the increase in wind velocity the ventilation rate increases linearly.

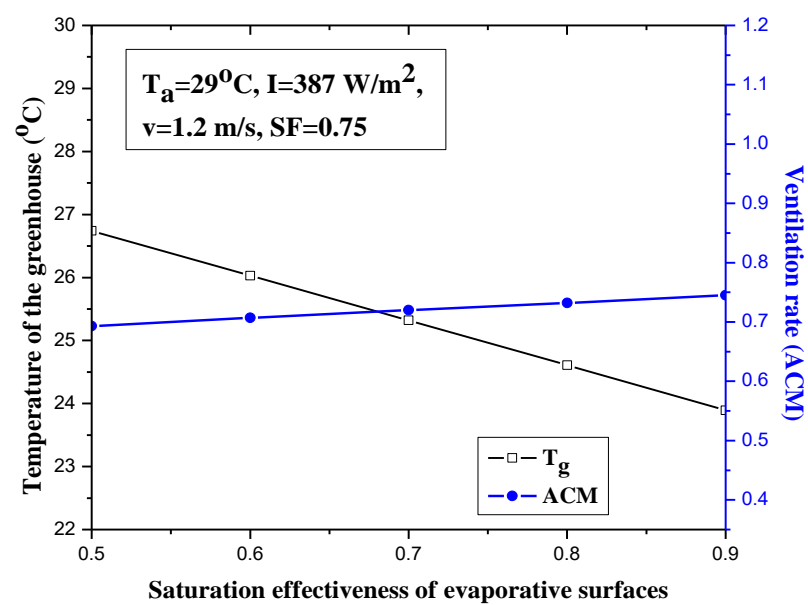

Fig. 7 Effect of saturation effectiveness on greenhouse temperature and ventilation rate

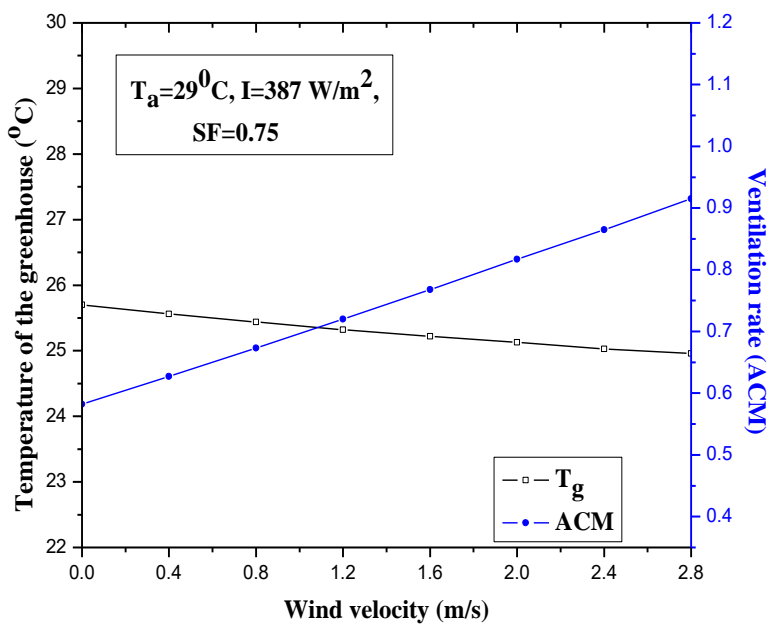

Fig. 8 Effect of wind velocity on greenhouse temperature and ventilation rate

\section{Conclusion}

The paper presents a modelling and analysis of a greenhouse system with provision for natural as well as fan assisted ventilation and having surrounding water body for evaporative cooling of air. In both of the cases, model predicts satisfactory results to moderate 
Citation: Misra, D. and Ghosh, S., (2017) Performance Study of a Floricultural Greenhouse Surrounded by Shallow Water Ponds. Int. Journal of Renewable Energy Development, 6(2),137-144, https://doi.org/10.14710/ijred.6.2.137-144

$\mathrm{P}$ a g e | 144

the greenhouse temperature. The natural ventilation with evaporative cooling has been considered with buoyant and wind effects and longitudinal continuous vents are used to provide sufficient vent area, which consequently increases natural ventilation flux. The variations of the results between natural and fanassisted ventilation are minimum during non peak radiation hours. Form the analysis it is evident that natural ventilation with evaporative cooling is very much effective for average sunshine months and fan assisted ventilation is only required for hot and dry months. The proposed greenhouse system reduces energy consumption as most of the time it can be operated without fan ventilation. Again, it has been observed that saturation effectiveness of the wetted surfaces plays a major role in controlling greenhouse temperature.

\section{References}

Ahmed, E. M., Abaas, O., Ahmed, M., Ismail, M. R. (2011) Performance evaluation of three different types of local evaporative cooling pads in greenhouses in Sudan. Saudi Journal of Biological Sciences, 18, 45-51.

Arbel, A., Yekutieli, O., Barak, M. (1999) Performance of a fog system for cooling greenhouses. Journal of Agricultural Engineering Research 72 (2), 129-136.

Castilla, N. \& Hernandez, J. (2007) Greenhouse technological packages for high-quality crop production. Acta Horticulture, 761, 285-297.

Dayan, J., Dayan, E., Strassberg,Y., Presnov, E. (2004) Simulation and control of ventilation rates in greenhouses. Mathematics and Computers in Simulation, 65, 3-17.

Fuchs, M., Dayan, M., Presnov, E. (2006) Evaporative cooling of a ventilated greenhouse rose crop. Agricultural and Forest Meteorology, 138, 203-215.

Ganguly, A. \& Ghosh, S. (2007) Modeling and analysis of a fanpad ventilated floricultural greenhouse. Energy and Buildings, 39, 1092-1097.

Ganguly, A. \& Ghosh, S. (2009) Model development and experimental validation of a floriculture greenhouse under natural ventilation. Energy and Buildings, 41, 521-527.

Jain,D. \& Tiwari, G.N. (2002) Modeling and optimal design of evaporative cooling system in controlled environment greenhouse. Energy Conversion and Management, 43, 2235-2250.

Kittas, C., Boulard, T., Papadakis, G. (1997) Natural ventilation of a greenhouse with ridge and side openings: sensitivity to temperature and wind effects. Transactions of ASAE, 40, $415-425$.

Misra, D. \& Ghosh, S. (2013) Thermal modeling of a ridgeventilated greenhouse equipped with longitudinally distributed evaporative cooling pads. Int. J. Emerg. Technol. Adv. Eng., 3 (Special Issue 3), 348-355.

Misra, D. \& Ghosh. S. (2017) Microclimatic modeling and analysis of a fog-Cooled naturally ventilated greenhouse, International Journal of Environment, Agriculture and Biotechnology, 2(2), 997-1002.

Papadakis, G., Mermier, M., Meneses, J.F., Boulard, T. (1996) Measurement and analysis of air exchange rates in a greenhouse with continuous roof and side openings. Journal of Agricultural Engineering Research, 63, 219-228.

Romantchik, E., Ríos, E., Sánchez, E., López, I. (2017) Determination of energy to be supplied by photovoltaic systems for fan-pad systems in cooling process of greenhouses. Applied Thermal Engineering, 114, 1161-1168.

Roy, J.C., Boulard, T., Kittas, C., Wang, S. (2002) Convective and Ventilation Transfers in Greenhouses, Part 1: the Greenhouse considered as a Perfectly Stirred Tank. Biosystems Engineering, 83, 1-20.

Shu-zen, L., Young, H.E., Zhang, Y., Xiang-wen, M. (2005) Prediction and analysis model of temperature and its application to natural ventilation multi span greenhouse equipped with insect proof screen. Journal of Zhejiang University Science, 6, 523-529.

Teitel, M. \& Tanny, J. (1999) Natural ventilation of greenhouses: experiments and model. Agricultural and Forest Meteorology, 96, 59-70.

Thipe, E. L., Workneh, T., Odindo, A., Laing. M. (2017) Greenhouse Technology for Agriculture under Arid Conditions. Sustainable Agriculture Reviews, 22, 37-55.

Tiwari, G. N. Greenhouse Technology for Controlled Environment. (2003) Narosa Publishing House, February, New Delhi, India.

Tiwari, G.N. (2002) Solar Energy-Fundamentals, Design, Modeling and Application. Narosa Publishing, May,

White, R. A. J. (2015) Vent, fog and fan, a cooling system for large greenhouses in hot weather with low humidity, Acta Horticulture, 1107, 61-66. 